\title{
Uji Lipid pada Minyak Kelapa, Margarin, dan Gliserol
}

\author{
Lipid Tests on Coconut Oil, Margarin, and Glycerol \\ Yolla Arinda Nur Fitriana ${ }^{1}$, Ardhista Shabrina Fitri ${ }^{2}$ \\ ${ }^{1}$ Teknologi Pangan - Universitas Ahmad Dahlan, Yogyakarta, Indonesia \\ ${ }^{2}$ Farmasi - Universitas Muhammadiyah Purwokerto, Purwokerto, Indonesia \\ 1'yolla.anf@gmail.com \\ ${ }^{2}$ ardhista.fitri@ump.ac.id
}

\begin{abstract}
ABSTRAK
Minyak kelapa sebagai salah satu produk pangan cair banyak digunakan dalam kehidupan sehari-hari. Sementara minyak kelapa juga banyak digunakan margarin yang merupakan produk pangan dengan tekstur setengah padat. Kedua produk pangan ini memiliki kandungan asam lemak. Sebagai komponen utama dari semua lemak dan minyak, gliserol memiliki kegunaan dalam pembuatan berbagai produk pangan, industri, dan farmasi. Guna mengantisipasi ketidakseimbangan penggunaan minyak kelapa, margarin, dan gliserol dalam produk pangan, maka dilakukan uji lipid berupa uji ketidakjenuhan dan uji akrolein. Uji ketidakjenuhan dilakukan terhadap minyak kelapa dan margarin, sedangkan uji akrolein diterapkan pada minyak kelapa dan gliserol. Penelitian ini menghasilkan informasi bahwa: 1) minyak kelapa mengandung asam lemak jenuh yang ditandai dengan hilangnya warna merah muda, sedangkan margarin mengandung asam lemak tidak jenuh; 2) minyak kelapa dan gliserol menghasilkan bau tengik menyengat pada uji akrolein yang disebabkan oleh terdehidrasinya asam lemak.
\end{abstract}

Kata-kata kunci: uji Lipid, minyak kelapa, margarin, gliserol

\begin{abstract}
Coconut oil as a liquid food product is widely used in daily life. While coconut oil is also widely used margarine which is a food product with a semi-solid texture. Both of these food products contain fatty acids. As a major component of all fats and oils, glycerol has uses in making various food, industrial and pharmaceutical products. To anticipate an imbalance in the use of coconut oil, margarine, and glycerol in food products, a lipid test is carried out in the form of unsaturation and acrolein tests. The unsaturation test is carried out on coconut oil and margarine, while the acrolein test is applied to coconut oil and glycerol. This research produces information that: 1) coconut oil contains saturated fatty acids which are characterized by a loss of pink color, while margarine contains unsaturated fatty acids; 2) coconut oil and glycerol produce a pungent odor in the acrolein test caused by the dehydration of fatty acids.
\end{abstract}

Keywords: Lipid test, coconut oil, margarine, glycerol.

\section{PENDAHULUAN}

Di antara sekian banyak jenis minyak, minyak kelapalah yang paling sering digunakan. Minyak kelapa kasar mengandung komponen bukan minyak seperti fosfatida, gum, sterol (0,06\%-0,8\%), tokoferol (0,003\%), dan asam lemak nenas kurang dari $5 \%$. Warna pada minyak disebabkan oleh adanya pigmen-pigmen warna alam karoten yang merupakan hidrokarbon tidak jenuh (Ketaren, 1986). Sifat minyak kelapa yang terpenting 
adalah tidak mencair tahap demi tahap seperti lemak yang lain, akan tetapi langsung berubah menjadi cair karena titik cair asam lemak penyusunnya berdekatan (Murdijati, 1980).

Margarin merupakan produk pangan yang memiliki tekstur setengah padat dengan karakteristik sifat fisik dan kimia yang sangat bergantung pada komponen penyusunnya. Margarin merupakan sistem emulsi yang terdiri dari $20 \%$ air di dalam minyak $80 \%$. Kandungan bahan baku margarin memiliki kerapuhan dan daya tahan tinggi terhadap pengembangan (Yuwono et al., 2017).

Gliserol merupakan sebuah komponen utama dari semua lemak dan minyak, dalam bentuk ester yang disebut gliserida. Gliserol ditemukan untuk memiliki berbagai macam kegunaan dalam pembuatan berbagai produk dalam negeri, industri, dan farmasi. Gliserol (CH2OH.CHOH.CH2OH atau propana-1, 2, 3-triol) memiliki bentuk murni, yaitu bening, tidak berbau, dan kental. Gliserol dapat larut dalam air dan alkohol, sedikit larut dalam banyak pelarut umum seperti eter dan dioksan, dan tidak larut dalam hidrokarbon. Pada suhu rendah, gliserol kadang-kadang membentuk kristal yang cenderung meleleh pada $17,9^{\circ} \mathrm{C}$. Gliserol cair mendidih pada $290^{\circ} \mathrm{C}$ di bawah rekanan atmosfer normal (Van Gerpen, 2005).

Uji lipid dalam penelitian ini meliputi uji ketidakjenuhan dan uji akrolein. Derajat ketidakjenuhan dinyatakan dengan bilangan iodin. Jumlah garam yang dapat diserap oleh 100 gram lemak untuk reaksi penjenuhan. Semakin besar bilangan iodin semakin tinggi ketidakjenuhannya (Salirawati, 2007). Uji ketidakjenuhan digunakan untuk mengetahui asam lemak yang diuji merupakan asam lemak jenuh atau asam lemak tidak jenuh. Iod Hubl digunakan sebagai indikator perubahan. Reaksi positif ditandai dengan timbulnya warna merah muda, lalu warna kembali lagi menjadi warna asal (bening). Warna yang kembali ke warna asal menandakan bahwa banyak ikatan rangkap pada rantai hidrokarbon asam lemak. Warna merah muda hilang selama reaksi menunjukkan bahwa asam lemak tak jenuh telah mereduksi pereaksi Iod Hubl. Sementara itu, uji akrolein merupakan uji pada gliserol dalam bentuk bebas atau yang terdapat pada lemak dan minyak bila mengalami dehidrasi akan membentuk aldehid aksilat atau disebut juga dengan akrolein. Reaksi positif terjadi apabila lemak yang dipanaskan dan terdehidrasi memiliki bau lemak terbakar dengan asap putih.

Berdasarkan uraian di atas, penelitian ini bertujuan untuk mengetahui ketidakjenuhan sampel minyak kelapa dan margarin, serta mengetahui perubahan bau pada senyawa minyak kelapa dan gliserol melalui uji akrolein.

\section{METODE}

\section{A. Alat dan Bahan}

Alat yang digunakan pada percobaan ini adalah tabung reaksi, pipet ukur $5 \mathrm{ml}$, propet, pipet tetes, vortex mixer merk Corning, pipet ukur $1 \mathrm{ml}$, spatula, pemanas bunsen, korek api, pipet ukur $10 \mathrm{ml}$, penjepit, dan gelas arloji. Sementara itu, bahan yang digunakan pada percobaan ini adalah aquades, kloroform 40\%, Iod Hubl, minyak kelapa, margarin, air sabun, gliserol, KHSO4, $\mathrm{KOH} 0,5 \mathrm{~N}$ alkoholis, aquades, $\mathrm{HCL} 0,5 \mathrm{~N}, \mathrm{NaOH}$ $40 \%$, larutan $\mathrm{NaCl}$ jenuh, eter, dan kertas lakmus.

\section{B. Langkah Uji}

1. Uji Ketidakjenuhan

- Memasukkan $4 \mathrm{ml}$ kloroform dan 4 tetes iod hubl ke dalam tabung reaksi, kemudian dikocok menggunakan vortex hingga terbentuk warna merah muda (larutan A). 
- Memasukkan $1 \mathrm{ml}$ minyak kelapa, 1 sendok margarin dan $1 \mathrm{ml}$ eter, dan $1 \mathrm{ml}$ air sabun ke dalam masing masing tabung reaksi. Kemudian, tiap tabung reaksi ditambahkan larutan A dan dikocok menggunakan vortex, lalu diamati.

\section{Uji Akrolein}

- tiga tetes minyak kelapa dan 3 tetes gliserol masing-masing dimasukkan ke dalam tabung reaksi.

- kemudian ditambahkan 1 sendok KHSO4 pada tiap tabung reaksi dan dipanaskan, diamati baunya.

\section{HASIL DAN PEMBAHASAN}

Lipid merupakan golongan senyawa organik kedua yang menjadi sumber makanan dan kira-kira $40 \%$ dari yang manusia makan setiap hari. Suatu lipid didefinisikan sebagai senyawa organik yang terdapat dalam alam serta tak larut dalam air, tetapi larut dalam pelarut organik non-polar seperti suatu hidrokarbon atau dietil-eter (Fessenden and Fessenden, 1997). Sifat dari lipid antara lain, lipid mudah larut dalam pelarut non polar seperti kloroform, karbon disulfida dan lainnya, karena semakin panjang rantai asam lemak kelarutan dalam air akan berkurang. Selain itu, jika asam lemak yang terdapat dalam minyak memiliki berat molekul rendah maka jumlah gliseridanya semakin banyak dan menyebabkan bilangan penyabunan meningkat. Serta, lipid dalam mengalami kerusakan yang ditandai dengan munculnya perubahan bau dan cita rasa yang disebabkan oleh pengaruh enzim, pengaruh mikroba, dan reaksi oksidasi oleh oksigen udara (Deman, 1997). Lipid dapat diekstrak dari sel dan jaringan oleh pelarut non polar yang mengandung unsur-unsur karbon, hidrogen, dan oksigen, kadang-kadang juga mengandung nitrogen dan fosfor. Apabila lipid dihidrolisis akan menghasilkan asam lemak.

Ada beberapa cara penggolongan lipid, yaitu lipid dibagi menjadi 3 golongan besar yaitu lipid sederhana (ester asam lemak dengan alkohol) contohnya lemak atau gliserida dan lilin (waxes), lipid gabungan (ester asam lemak yang mempunyai gugus tambahan) contohnya fosfolipid dan serebrosida, dan derivat lipid (senyawa yang dihasilkan oleh proses hidrolisis lipid) contohnya asam lemak, gliserol, dan sterol. Disamping itu, berdasarkan sifat kimia yang penting, lipid dapat dibagi menjadi 2 golongan besar, yakni lipid yang dapat disabunkan contohnya lemak, dan lipid yang tidak dapat disabunkan contohnya steroid (Poedjiadi and Supriyanti, 2009). Poedjiadi (1994) mengatakan bahwa Lipid mempunyai fungsi sebagai sumber energi yang efisien ketika tersimpan dalam jaringan adiposa bagi tubuh, sebagai sumber asam lemak esensial, sebagai pelarut vitamin A, D, E, dan K, sebagai penyekat panas di sekeliling organ tertentu, dan sebagai penyekat listrik untuk perambatan cepat pada syaraf bermyelin.

Lipid mempunyai fungsi terbesar sebagai sumber energi yang efisien ketika tersimpan dalam jaringan adiposa bagi tubuh. Selain itu, lipid berfungsi sebagai sumber asam lemak essensial, sebagai pelarut vitamin A, D, E, dan K, dan sebagai penyekat panas di sekeliling organ tertentu. Fungsi lain lipid yaitu sebagai penyekat listrik untuk perambatan cepat syaraf bermyelin (Poedjiadi, 1994).

Asam lemak merupakan asam organik berantai panjang yang mempunyai atom karbon dari 4 sampai 24. Asam lemak mempunyai gugus karboksil tunggal dan ekor hidrokarbon non polar yang panjang yang menyebabkan kebanyakan lipid bersifat tidak larut dalam air dan tampak berminyak atau berlemak (Lehninger, 1998). Penyusun asam lemak dibedakan menjadi dua bagian yaitu lemak jenuh dan tidak jenuh. Lemak jenuh banyak mengandung komponen asam lemak jenuh dan memiliki ikatan rangkap, sehingga bersifat padat/solid pada suhu ruang. Asam lemak jenuh sering disebut lemak. Sedangkan asam lemak tidak jenuh molekulnya mempunyai ikatan rangkap pada rantai karbonnya. 
Lipid yang mengandung asam lemak tak jenuh bersifat cair pada suhu kamar. Asam lemak tidak jenuh ini biasa disebut minyak (Ketaren, 2005). Dari segi gizinya, asam lemak mengandung energi tinggi (menghasikan banyak ATP). Karena itu, kebutuhan lemak dalam pangan diperlukan. Diet rendah lemak dilakukan untuk menurunkan asupan energi dari makanan. Asam lemak tak jenuh dianggap bernilai gizi lebih baik karena lebih reaktif dan merupakan antioksidan di dalam tubuh (Sudarmadji and Haryono, 2007).

\section{A. Uji Ketidakjenuhan}

Hasil uji ketidakjenuhan pada lipid terhadap minyak kelapa dan margarin disajikan pada Tabel 1.

Tabel 1. Hasil Uji Ketidakjenuhan pada Lipid

\begin{tabular}{ccll}
\hline \multirow{2}{*}{ Sampel } & \multicolumn{2}{c}{ Perubahan Warna } & \multirow{2}{*}{ Keterangan } \\
\cline { 2 - 3 } & \multicolumn{1}{c}{ Sebelum } & \multicolumn{1}{c}{ Sesudah } & \multirow{2}{*}{ Jenuh } \\
1. Minyak Kelapa & Kuning bening & $\begin{array}{l}\text { Pink bening } \\
\text { kemudian putih } \\
\text { bening }\end{array}$ & \\
2. Margarin & Kuning & Kuning & Tidak jenuh \\
\hline
\end{tabular}

Percobaan ini dilakukan untuk menentukan ketidakjenuhan suatu lemak. Minyak mengandung triasilgliserol dengan $80-85 \%$ asam lemak jenuh. Pada hasil percobaan, minyak kelapa memberikan hasil positif mengandung asam lemak jenuh yang ditandai dengan hilangnya warna merah muda, sedangkan margarin memiliki kandungan asam lemak tidak jenuh karena warna margarin tetap berwarna kuning.

\section{B. Uji Akrolein}

Uji akrolein pada lipid terhadap minyak kelapa dan gliserol dipaparkan pada Tabel 2.

Tabel 2. Hasil Uji Akrolein pada Lipid

\begin{tabular}{|c|c|c|c|c|}
\hline & \multirow{2}{*}{ Sampel } & \multicolumn{2}{|c|}{ Perubahan Bau } & \multirow{2}{*}{ Keterangan } \\
\hline & & Sebelum & Sesudah & \\
\hline & $\begin{array}{l}\text { Minyak } \\
\text { Kelapa }\end{array}$ & Bau minyak & Tengik & $(+)$ akrolein \\
\hline 2. & Gliserol & Tidak berbau & Tengik & $(+)$ akrolein \\
\hline
\end{tabular}

Pada percobaan ini, digunakan sampel minyak kelapa dan gliserol. Percobaan ini bertujuan untuk menunjukkan bahwa minyak mengalami dehidrasi yang akan menimbulkan akrolein. Dari hasil percobaan, kedua sampel memiliki bau tengik menyengat setelah dilakukan uji akrolein. Ketengikan dari kedua sampel disebabkan oleh adanya reaksi antara molekul oksigen dengan asam lemak berikatan ganda. Ketengikan juga terjadi bila triasilgrilserol yang mengandung asam lemak tak jenuh mengalami proses oksidasi.

\section{KESIMPULAN}

Kesimpulan dari hasil penelitian ini adalah:

1. Minyak kelapa mengandung asam lemak jenuh yang ditandai dengan hilangnya warna merah muda, sedangkan margarin mengandung asam lemak tidak jenuh. 
2. Minyak kelapa dan gliserol menghasilkan bau tengik menyengat pada uji akrolein yang disebabkan oleh terdehidrasinya asam lemak.

\section{DAFTAR PUSTAKA}

Deman, J.M., 1997. Kimia makanan, Bandung: Penerbit ITB.

Fessenden, R.J. and Fessenden, J.S., 1997. Dasar-dasar kimia organik (diterjemahkan oleh Pudjaatmakan, A. H.), Jakarta: Erlangga.

Van Gerpen, J., 2005. Biodiesel processing and production. Fuel processing technology, 86(10), pp.1097-1107.

Ketaren, S., 1986. Pengantar Teknologi Minyak dan Lemak Pangan, Jakarta: UIPress.

Ketaren, S., 2005. Teknologi Minyak dan Lemak Pangan. Universitas Indonesia.

Lehninger, A.L., 1998. Dasar-Dasar Biokimia Jilid 1., Jakarta: Erlangga.

Murdijati, G., 1980. Minyak: Sumber, Penanganan, Pengelolaan, dan Pemurnian.

Poedjiadi, A., 1994. Dasar-dasar Biokimia, Jakarta: Penerbit Universitas Indonesia.

Poedjiadi, A. and Supriyanti, F.M., 2009. Dasar-dasar biokimia Edisi Revi., Jakarta: UIPress.

Salirawati, D., 2007. Belajar Kimia Menarik Untuk Kimia SMA Kelas XII, Jakarta: Grasindo.

Sudarmadji, S. and Haryono, B., 2007. Analisa Bahan Makanan dan Pertanian, Yogyakarta: Liberty.

Yuwono, T., Sumeidiana, I., Ondho, Y.S. and Kurnianto, E., 2017. Gonadal hormones level and morphometric traits in cow deliveres twin and single calves. Journal of Indonesian Tropical Animal Agriculture, 42(2), pp.128-132. 